\title{
Discurso de posse no cargo de Diretor da Faculdade de Direito da USP, realizada na Reitoria em 13/07/1990.
}

Magnifico Reitor Roberto Leal Lobo e Silva Filho;

Magnifico Vice-Reitor Professor Ruy Laurent;

Exm Sr. Deputado Federal, José Egreja;

$\operatorname{Exm}^{2}$ Sr. Dr. Milton Luiz Pereira, Digníssimo Presidente do Tribunal Federal da $3^{\mathrm{g}}$

Região;

Exm Sr. Secretário de Estado, Paulo Salvador Frontini;

Exm $^{2}$ Sr. Pró-Reitor de Graduação Professor Celso de Rui Beisiegel;

Exme Sr. Pró-Reitor de Cultura e Extensão Universitária, Professor João Alexandre Costa Barbosa;

$\mathrm{Exm}^{2}$ Sr. Professor Emérito Goffredo da Silva Telles;

$\mathrm{Exm}^{2}$ Sr. Professor Dalmo de Abreu Dallari;

Exma. Sra. Secretária Geral, Professora Lor Cury.

Minha Senhoras e Meus Senhores.

Nesta espécie de apresentação que o Diretor, a quem se dá posse, faz de seus planos futuros, eu gostaria, de início, de voltar brevemente ao passado, para agradecer, quer minha escolha pelos companheiros de Faculdade e, por "companheiros", significo professores, e funcionários -, quer minha posterior designação pelo Magnífico Reitor.

Gostaria, ainda, de deixar consignados meus elogios a meu antecessor, Professor Dalmo de Abreu Dallari. Especialmente, em três pontos, dois bem visíveis e o outro, invisível, realizou ele grande gestão; os visíveis são: a introdução da informática na Faculdade de Direito - estão informatizadas a administração, a biblioteca e há cursos regulares para estudantes e professores - e a construção do prédio de apoio, que deverá trazer realmente um "novo tempo" para o ensino nas Arcadas. A atividade invisível foi uma espécie de resgate da condição dos funcionários da Escola, hoje organizados e participantes, uma "pequena grande obra", bem de acordo com o caráter humanista do professor Dalmo de Abreu Dallari.

Quanto ao futuro, tenho consciência de que a inauguração do prédio novo trará algumas dificuldades de adaptação: desde a distribuição dos novos espaços até a introdução de métodos de ensino mais atualizados. São, porém, dificuldades bemvindas, porque as classes regulares da Faculdade de Direito são compostas, por força das condições ainda existentes, de 110/120 alunos e, até hoje, convém dizer, na nossa Escola, nenhum professor tem sala própria, onde possa receber e orientar seus alunos.

Inteiramente de acordo com a prioridade dada pela Reitoria ao ensino de graduação, espero que, com as novas perspectivas, também a estrutura curricular possa ser renovada, com a participação de professores e alunos, a fim de obter 
maior adequação à realidade nacional e corrigir senões, consistentes em falta de harmonia nos programas das disciplinas e em rigidez no currículo propriamente dito.

Quanto às relações da Escola com as demais unidades da USP, seria importante que as informaçōes sobre pesquisas que estão sendo realizadas, especialmente na FEA, na Faculdade de Educação e na Faculdade de Filosofia, fossem, pelo menos semestralmente, cruzadas com as informaçōes sobre pesquisas que se realizam na Faculdade de Direito. Na condição de membro da CERT, pude verificar que há temas praticamente idênticos, tratados em uma e outra unidade, como os relativos às funçōes do Estado, à redução ou acréscimo de salário, aos direitos humanos e à geopolítica.

Por outro lado, a introdução de um "posto avançado" da Faculdade de Direito, aqui, no campus central, é uma idéia que, levada adiante, poderá produzir ótimos resultados. Não só traria maior integração da Faculdade, na USP, como poderia abrir oportunidade a uma espécie de curso experimental na área de Humanidades, um projeto-piloto, consistente, por exemplo, segundo idéia do PróReitor de Graduação, num círculo básico de formação profunda em Antropologia, inclusive Antropologia Filosófica, ao qual se seguiriam as especializações: direito, educação, filosofia, história, jornalismo, etc.

Magnífico Reitor, minhas senhoras e meus senhores, a Faculdade de Direito tem tido tradicionalmente uma dupla função na sociedade brasileira. Aquilo de que vínhamos falando até aqui diz respeito à primeira função: é o papel profissionalizante, de formação de quadros. Trata-se, como já diziam os velhos Estatutos do Visconde de Cachoeira, de formar "homens hábeis para serem um dia sábios magistrados e peritos advogados, de que tanto se carece", bem como "dignos deputados e senadores para ocuparem os lugares diplomáticos e mais empregos do Estado". Como demonstração do comprimento desta função, a Faculdade de Direito poderia arrolar aqueles inúmeros ministros, senadores e conselheiros do Império, já chamados de "72 notáveis", ou de 45 governadores (ou presidentes) do Estado de São Paulo, ou os 10 presidentes da República que passaram pelos bancos acadêmicos: Prudente de Morais, Campos Salles, Rodrigaes Alves, Afonso Pena, Venceslau Brás, Delfim Moreira, Artur Bernardes, Washington Luis, José Linhares e Jânio Quadros. Mais modestamente, a Faculdade poderia, ainda, dar como prova do adimplemento de seu dever profissionalizante o fato de seus formandos continuarem a obter os primeiros lugares nos concursos à magistratura e ao ministério público.

Mas, paralelamente a esta função, que se poderia qualificar, sem qualquer desdouro, de conservação e aprimoramento da sociedade existente, tem também a Faculdade de Direito um papel inovador, uma tradição de inconformismo, de crítica social, admiravelmente expressa no lema do Centro Acadêmico XI de Agosto: ridendo, castigat mores, "pelo riso, corrigem-se os costumes". A mim, este lema agrada: a primeira parte, o ridendo, indica a alegria de viver, o riso, o senso do ridículo; e a segunda, o castigat mores, a consciência de que o homem é um ser social que se aperfeiçoa permanentemente. 
Foi esta segunda tradição, de crítica, que levou a Faculdade de Direito, no passado, por seus estudantes e por muitos de seus professores, a ser abolicionista, no tempo da escravidão, republicana, no tempo da monarquia, constitucionalista, quando o país não tinha lei maior, e democrática, nos tempos de ditadura.

Ora, também essa tradição, "política", no melhor sentido, eu não gostaria de ver extinta. O Brasil é, hoje, um país sem vontade nacional. Falta-nos coesão e há, pelo menos, três sérios riscos de ruptura: uma horizontal, geográfica, entre Estados do Norte e Estados do Sul; outra vertical, social, entre as camadas de nível econômico mais elevado (identificadas antes com os países desenvolvidos) e a própria população brasileira mais simples; e a terceira, uma espécie de ruptura cultural, entre um presente, que parece ter perdido a cadeia de uma continuidade histórica, e o passado nacional. Oxalá, a Faculdade de Direito mantenha sua tradição de participação política no mais alto sentido, porque, como se percebe, há muito que fazer. Para isso temos disposição.

Magnífico Reitor, minhas senhoras e meus senhores. Na minha pequenez, na minha falta de carisma, ouso terminar pronunciando, como manifestação de desejo, uma notável frase evangélica, inscrita em uma das igrejas de Roma: "Ignem veni mittere in terram et quid volo nisi ut accendatur?", "Vim trazer o fogo à Terra e que quero senão que arda?"

São Paulo, 13 de julho de 1990

Antonio Junqueira de Azevedo 


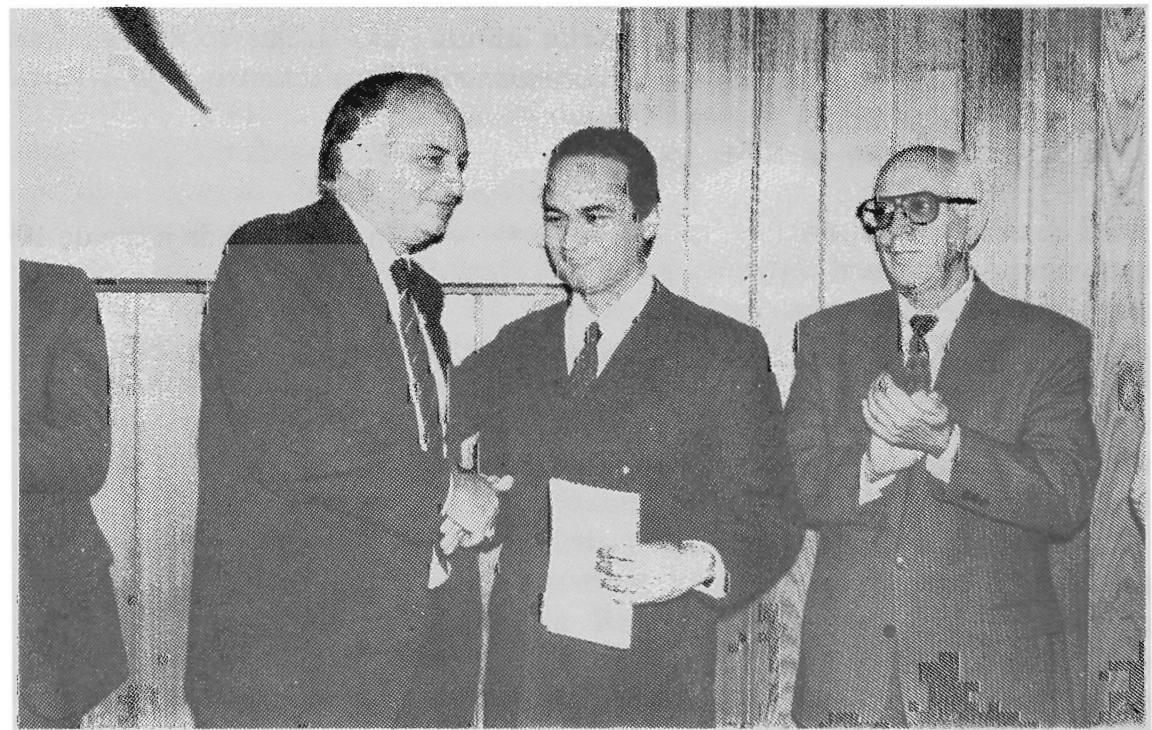

O professor Antonio Junqueira de Azevedo ladeado pelo reitor Roberto Leal Lobo e Silva Filho (à esq.) e professor Dalmo de Abreu Dallari (à dir.) 